\title{
Níveis de proteína bruta e suplementação de aminoácidos em rações para leitoas mantidas em ambiente termoneutro dos 60 aos $100 \mathrm{~kg}^{1}$
}

\author{
Uislei Antonio Dias Orlando², Rita Flávia Miranda de Oliveira ${ }^{3}$, Juarez Lopes Donzele ${ }^{3}$, Rony \\ Antonio Ferreira ${ }^{4}$, Francisco Carlos de Oliveira Silva ${ }^{5}$, Roberta Gomes Marçal Vieira Vaz ${ }^{6}$, \\ Jefferson Costa de Siqueira ${ }^{6}$
}

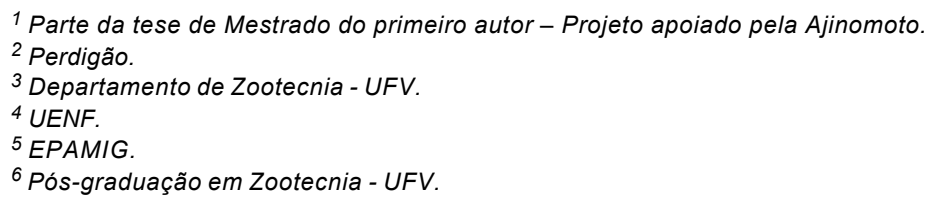

RESUMO - Foi conduzido um experimento para se avaliarem níveis de proteína bruta (PB) com suplementação de aminoácidos sintéticos em rações para leitoas mantidas em ambiente termoneutro. Trinta e cinco leitoas mestiças (Landrace $\mathrm{x}$ Large White) com peso médio inicial de $60,5 \mathrm{~kg}$ foram distribuídas em delineamento experimental inteiramente ao acaso, com cinco tratamentos $(17,3 ; 16,0 ; 14,7 ; 13,4$ e 12,1\% PB, com suplementação de lisina, metionina, triptofano, treonina e valina, para se manter a qualidade protéica entre os tratamentos), sete repetições e um animal por unidade experimental. As rações experimentais foram fornecidas à vontade até o final do experimento, quando os animais atingiram o peso médio de $100,6 \mathrm{~kg}$. Não se observou efeito da redução do nível de proteína bruta da ração sobre o desempenho (consumo de ração, ganho de peso e conversão alimentar) dos animais. As variáveis avaliadas na carcaça (comprimento da carcaça, área-de-olho de lombo, espessura de toucinho, rendimentos de carcaça, de carne magra, de gordura e de pernil) também não foram influenciadas pela redução do nível de PB das rações. Os tratamentos influenciaram os pesos absoluto e relativo do fígado, observando-se os maiores valores nos animais que receberam a ração com 16,0\% de PB. A redução do nível de PB de 17,3 para 12,1\% em rações para leitoas mantidas em ambiente termoneutro dos 60 aos $100 \mathrm{~kg}$ não prejudica o desempenho, desde que as rações sejam devidamente suplementadas com os aminoácidos essenciais limitantes.

Palavras-chave: aminoácidos, leitoas, nutrição, temperatura, terminação

\section{Dietary crude protein levels with amino acid supplementation for gilts from 60 to $100 \mathrm{~kg}$ on termoneutral environment}

\begin{abstract}
A trial was conduced to evaluate decreasing levels of CP with amino acid supplementation on performance of gilts on thermoneutral environment. Thirty-five crossbreed gilts (Landrace x Large White) averaging initial weight of $60.5 \mathrm{~kg}$ were allotted to a complete randomized design with five treatments $(17.3,16,14.7,13.4$ and $12.1 \%$ of $\mathrm{CP})$ of seven replications (one animal per experimental unit). The experimental diets were fed ad libitum until the end of the experiment when the animals reached the average weight of $100.6 \mathrm{~kg}$. No effect of decreasing dietary levels of crude protein on performance (feed intake, weight gain and feed gain ratio) was observed. Decreasing dietary CP levels did not affect the carcass characteristics (carcass length, loin eye area, backfat thickness and carcass, lean growth, fat and ham yield), but affected the relative and absolute weights of liver and the greatest value was observed in animals fed diet with $16.0 \%$ of CP. Decreasing dietary CP levels from 17.3 to $12.1 \%$ for gilts from 60 to $100 \mathrm{~kg}$ on thermoneutral environment did not affect performance, since diets are supplemented with limiting essential amino acids.
\end{abstract}

Key Words: amino acids, finishing, gilts, nutrition, temperature

\section{Introdução}

A crescente preocupação em controlar os poluidores potenciais do meio ambiente tem demandado estratégias nutricionais que promovam, entre outros fatores, a redução do potencial poluente dos dejetos dos suínos. Uma alterna- tiva nutricional avaliada nos últimos anos tem sido a diminuição do nível de proteína bruta da ração com concomitante suplementação de aminoácidos sintéticos (Baker et al., 1993; Cromwell, 1996; Reese \& Koelsch, 2000; Carlson, 2001; Ford, 2003). Essa alternativa tem sido justificada considerando-se que os aminoácidos sintéticos, ao substituírem

Correspondências devem ser enviadas para: flavia@ufv.br 
a proteína bruta, podem reduzir as perdas de nitrogênio sem reflexo negativo no desempenho dos animais.

A estratégia de redução dos níveis de proteína bruta, por meio da substituição por aminoácidos sintéticos pode ainda proporcionar relação de aminoácidos mais próxima ao perfil da proteína ideal e, conseqüentemente, diminuir a quantidade de nitrogênio nos dejetos. Com o uso dos aminoácidos sintéticos lisina, metionina, treonina e triptofano, observa-se redução de até $40 \%$ na excreção de nitrogênio nas fezes e na urina de suínos (Ford, 2003). Entretanto, é necessário estabelecer o limite de redução da proteína bruta (sabe-se que suínos necessitam de determinada quantia de aminoácidos não-essenciais) e quais aminoácidos podem substituir essa proteína.

Além disso, o desempenho e a fisiologia dos animais podem ser influenciados pelo ambiente térmico em que são criados, de modo que a redução do nível de proteína da ração pode proporcionar desempenho diferente conforme o ambiente em que são mantidos (Oliveira, 1996; Edmonds et al., 1998). Tem-se observado que suínos mantidos em ambiente livre de estresse térmico, com adequado consumo de nutrientes essenciais, aumentam a deposição de proteína corporal e, conseqüentemente, o ganho de peso (Möhn \& De Lange, 1998).

Os efeitos tanto da temperatura ambiente quanto da redução dos níveis protéicos com simultânea suplementação de aminoácidos, mantendo-se a relação entre os aminoácidos essenciais e a lisina digestível, podem diferir quanto ao estádio de desenvolvimento e ao sexo do animal.

Nesse contexto, realizou-se este estudo com o objetivo de avaliar a redução dos níveis de proteína bruta com suplementação de aminoácidos, mantendo-se a relação entre os aminoácidos essências digestíveis e a lisina digestível e utilizando-se o conceito de proteína ideal, e seus efeitos sobre o desempenho e as características de carcaça de leitoas mestiças mantidas em ambiente termoneutro dos 30 aos $60 \mathrm{~kg}$.

\section{Material e Métodos}

O experimento foi conduzido nas câmaras climáticas do Laboratório de Bioclimatologia Animal do Departamento de Zootecnia do Centro de Ciências Agrárias da Universidade Federal de Viçosa, em Viçosa, MG.

Foram utilizadas 35 leitoas mestiças (Landrace x Large White) em fase de terminação, com peso inicial de $60,5 \pm 0,79 \mathrm{~kg}$, distribuídas em delineamento experimental inteiramente ao acaso, com cinco tratamentos $(17,3 ; 16,0 ; 14,7 ; 13,4$ e $12,1 \%$ de proteína bruta, com suplementação de lisina, metionina, triptofano, treonina e valina, para se manter a qualidade protéica entre os tratamentos), sete repetições e um animal por unidade experimental.

Os animais foram alojados em gaiolas metálicas suspensas, com piso ripado e laterais teladas, providas de comedouro semi-automático e bebedouro tipo chupeta. A limpeza das baias foi realizada diariamente, efetuando-se a raspagem dos dejetos.

A temperatura interna da sala foi mantida constante por meio de sistema de aquecimento e resfriamento, controlado por sensores instalados no centro das salas bioclimáticas, regulado para temperatura de $20^{\circ} \mathrm{C}$.

As condições internas da sala foram monitoradas diariamente, três vezes ao dia $(8,13$ e $18 \mathrm{~h})$, utilizando-se termômetros de bulbo seco e bulbo úmido, termômetros de máxima e de mínima e termômetro de globo negro, mantidos em um tripé no centro da sala, à meia-altura do corpo dos animais. As leituras dos termômetros foram, posteriormente, convertidas no índice de temperatura de globo e umidade (ITGU) segundo Buffington et al. (1981), caracterizando o ambiente térmico ao qual os animais foram mantidos.

As rações experimentais e suas composições centesimal e nutricional calculadas encontram-se na Tabela 1. Para serem isoenergéticas $(3.400 \mathrm{kcal} \mathrm{de} \mathrm{ED} / \mathrm{kg}$ ) e isolisínicas digestíveis $(0,767 \%)$, as rações foram formuladas à base de milho e farelo de soja, sendo suplementadas com pré-misturas de minerais e vitaminas, adicionando-se lisina sintética (L-lisina-HC178,5\%), conforme se reduziu o nível de PB. Os níveis de $\mathrm{PB}$ das rações experimentais foram obtidos ajustando-se as quantidades de milho e farelo de soja. Os demais aminoácidos (treonina, metionina, triptofano e valina) foram acrescentados à medida que suas relações com a lisina digestível ficaram abaixo das preconizadas na proteína ideal, como proposto por Füller (1996). Para o cálculo dos aminoácidos digestíveis dos ingredientes utilizados na formulação, foram aplicados os coeficientes de digestibilidade obtidos nas tabelas Rhodimet ... (1993).

Os animais foram pesados no início e ao final do período experimental para determinação do ganho de peso diário. As rações experimentais e a água foram fornecidas à vontade, efetuando-se a pesagem semanal da quantidade fornecida e das sobras, para posterior determinação dos consumos diários de ração e de lisina e da conversão alimentar.

No final do período experimental, quando atingiram $100,6 \pm 1,86 \mathrm{~kg}$, os animais foram submetidos a jejum alimentar por 24 horas, sendo, posteriormente, abatidos por dessensibilização e sangramento. Em seguida, procedeu-se à toalete e à evisceração das carcaças, para retirada dos órgãos. O fígado, os rins, o estômago e o intestino delgado foram retirados, pendurados à sombra, por 20 minutos, para que o sangue escorresse, e pesados. 
Tabela 1 - Composições centesimal e nutricional calculada das rações experimentais Table 1 - Ingredient (\%) composition of the experimental diets

\begin{tabular}{|c|c|c|c|c|c|}
\hline \multirow[t]{2}{*}{$\begin{array}{l}\text { Ingrediente } \\
\text { Ingredient }\end{array}$} & \multicolumn{5}{|c|}{$\begin{array}{c}\text { Nível de proteína bruta }(\%) \\
\text { Crude protein level }\end{array}$} \\
\hline & 17,3 & 16,0 & 14,7 & 13,4 & 12,1 \\
\hline Milho (Corn) $(7,75 \% \mathrm{~PB})^{1}$ & 72,441 & 75,646 & 78,677 & 81,641 & 84,550 \\
\hline Farelo soja (Soybean meal) $(45,5 \% \mathrm{~PB})^{1}$ & 25,130 & 21,700 & 18,325 & 14,964 & 11,610 \\
\hline Óleo de soja (Soybean oil) & 0,265 & 0,327 & 0,448 & 0,599 & 0,756 \\
\hline Fosfato bicálcico (Dicalcium phosphate) & 0,530 & 0,598 & 0,663 & 0,736 & 0,805 \\
\hline Calcário (Limestone) & 1,118 & 1,102 & 1,087 & 1,068 & 1,052 \\
\hline Mistura mineral ${ }^{2}$ (Mineral mix) & 0,100 & 0,100 & 0,100 & 0,100 & 0,100 \\
\hline Mistura vitamínica ${ }^{3}$ (Vitamin mix) & 0,100 & 0,100 & 0,100 & 0,100 & 0,100 \\
\hline Sal comum (Salt) & 0,306 & 0,310 & 0,312 & 0,316 & 0,320 \\
\hline BH T & 0,010 & 0,010 & 0,010 & 0,010 & 0,010 \\
\hline L-lisina $\mathrm{HCl}$ (L-lysine $\mathrm{HCl}$ ) & - & 0,100 & 0,199 & 0,298 & 0,396 \\
\hline DL-metionina (DL-methionine) & - & 0,007 & 0,035 & 0,062 & 0,090 \\
\hline L-treonina (L-threonine) & - & - & 0,041 & 0,085 & 0,130 \\
\hline L-triptofano (L-tryptophan) & - & - & 0,003 & 0,021 & 0,039 \\
\hline L-isoleucina (L-isoleucine) & - & - & - & - & 0,029 \\
\hline L-valina (L-valine) & - & - & - & - & 0,013 \\
\hline Total & 100,000 & 100,000 & 100,000 & 100,000 & 100,000 \\
\hline \multicolumn{6}{|l|}{$\begin{array}{l}\text { Composição calculada }{ }^{4} \\
\text { Calculated composition }\end{array}$} \\
\hline Proteína bruta (Crude protein) (\%) & 17,3 & 16,0 & 14,7 & 13,4 & 12,1 \\
\hline ED (Digestible energy) (kcal/kg) & 3.400 & 3.400 & 3.400 & 3.400 & 3.400 \\
\hline EM (Metabolizable energy) ( $\mathrm{kcal} / \mathrm{kg})$ & 3.260 & 3.260 & 3.260 & 3.260 & 3.260 \\
\hline Lisina total (Total lysine) (\%) & 0,880 & 0,871 & 0,862 & 0,854 & 0,805 \\
\hline Lisina digestível (Digestible lysine) (\%) & 0,767 & 0,767 & 0,767 & 0,767 & 0,767 \\
\hline Relação Lis:PB (Lys:CP ratio) (\%) & 5,09 & 5,44 & 5,86 & 6,37 & 6,65 \\
\hline Met + Cis digestível $(\%)($ Digestible methionine + cystine $)$ & 0,583 & 0,499 & 0,499 & 0,499 & 0,499 \\
\hline Treonina digestível (Digestible threonine) (\%) & 0,565 & 0,539 & 0,537 & 0,537 & 0,537 \\
\hline Triptofano digestível (Digestible tryptophan) (\%) & 0,179 & 0,160 & 0,146 & 0,146 & 0,146 \\
\hline Isoleucina digestível (Digestible isoleucine) (\%) & 0,651 & 0,596 & 0,541 & 0,486 & 0,437 \\
\hline Valina digestível (Digestible valine) (\%) & 0,718 & 0,665 & 0,613 & 0,561 & 0,495 \\
\hline Cálcio (Calcium) (\%) & 0,650 & 0,650 & 0,650 & 0,650 & 0,650 \\
\hline Fósforo disponível (Available phosphorus) (\%) & 0,320 & 0,320 & 0,320 & 0,320 & 0,320 \\
\hline Sódio (Sodium) (\%) & 0,160 & 0,160 & 0,160 & 0,160 & 0,160 \\
\hline
\end{tabular}

As carcaças inteiras, incluindo pés e cabeça, foram pesadas e serradas ao longo da coluna vertebral. As meiacarcaças foram pesadas separadamente e mantidas em câmara fria $\left(4 \mathrm{a} 8^{\circ} \mathrm{C}\right)$ por 24 horas. A meia-caracaça direita foi utilizada para aferiação da medida da área de olho-delombo e a esquerda, para a dissecação.

$\mathrm{Na}$ avaliação das carcaças, foram consideradas as seguintes medidas: comprimento de carcaça, estimado pelo Método Brasileiro de Classificação de Carcaça - CCMB (ABCS, 1973) e pelo Método Americano - CMA (Boggs \& Merkel, 1979); espessura de toucinho entre a última e a penúltima vértebras lombares (ETUL); espessura de toucinho a $6,5 \mathrm{~cm}$ da linha dorso-lombar $\left(\mathrm{ETP}_{2}\right)$; área de olho de lombo, à altura da última costela, com a cobertura de gordura correspondente, incluindo a pele (ABCS, 1973); rendimento de carcaça (expresso como peso da carcaça quente em relação ao peso de abate após jejum x 100); rendimento de gordura (expresso como o peso da gordura total, dissecada da carcaça, em relação ao peso da carcaça resfriada $x$ 100); e rendimento de pernil (expresso como o peso total do pernil em relação ao peso da meia carcaça resfriada x 100).

As análises estatísticas das variáveis de desempenho (ganho de peso, consumo de ração e conversão alimentar), de avaliação dos parâmetros da carcaça e de pesos dos órgãos foram realizadas pelo procedimento GLM do SAS, versão 8.00 (1999), em que a soma de quadrados dos tratamentos foi decomposta em contrastes ortogonais, conforme o modelo estatístico abaixo:

$$
\mathrm{Y}_{\mathrm{ij}}=\mu+\mathrm{E}_{\mathrm{i}}+\mathrm{e}_{\mathrm{ij}}
$$

em que $Y_{i j}=$ ganho de peso, consumo de ração, conversão alimentar, parâmetros de carcaça e pesos dos órgãos referentes ao nível de proteína i na repetição $j ; \mu=$ média geral 
da característica; $\mathrm{E}_{\mathrm{i}}=$ efeito do nível de proteína bruta $\mathrm{i}$, sendo $i=17,3 ; 16,0 ; 14,7 ; 13,4$ e $12,1 \%$ na ração; $e_{i j}=$ erro aleatório associado a cada observação.

A avaliação da possibilidade de redução da proteína bruta da ração com suplementação de aminoácidos foi feita utilizando-se os resultados de desempenho (ganho de peso, consumo de ração, conversão alimentar), dos consumos de lisina e energia digestíveis diários, do consumo de nitrogênio diário, da eficiência de utilização de nitrogênio para ganho e das características de carcaça.

\section{Resultados e Discussão}

A temperatura interna da sala manteve-se durante o período experimental em $20,2 \pm 1,5^{\circ} \mathrm{C}$, a umidade relativa em $71,8 \pm 6,6 \%$ e a temperatura de globo negro em $20,3 \pm 1,5^{\circ} \mathrm{C}$. O índice de temperatura de globo e umidade (ITGU) calculado no período foi de $66,7 \pm 1,9$. O valor de ITGU que caracterizou o ambiente termoneutro neste trabalho foi próximo aos 69,1 e 68,7 obtidos por Tavares et al. (2000) e Orlando et al. (2001), respectivamente, em suínos mantidos em condições de conforto térmico.

Os resultados de desempenho (ganho de peso, consumo de ração e conversão alimentar), consumos diários de lisina, de nitrogênio e de energia digestível e a eficiência de utilização de nitrogênio para ganho das leitoas são apresentados na Tabela 2.

O ganho de peso diário (GPD) não foi influenciado $(\mathrm{P}>0,10)$ pela redução do nível de proteína bruta $(\mathrm{PB})$ na ração. No entanto, verificou-se que os animais que receberam a ração com 12,1\% de PB apresentaram GPD 5\% maior que o obtido com a ração contendo $17,3 \%$ de PB.

Estes resultados estão de acordo com os encontrados por Kerr et al. (1995), Cromwell (1996), Tuitoek et al. (1997a) e Ford (2003), que também observaram a possibilidade de se reduzir o nível de $\mathrm{PB}$ da ração em três ou quatro unidades percentuais, sem alterar o GPD dos suínos em crescimento. O mesmo foi constatado por Pieterse et al. (2000), em estudos conduzidos com suínos na fase de terminação, em que o nível de proteína foi reduzido em seis pontos percentuais.

Os resultados de GPD obtidos neste estudo diferem dos relatados por Miller et al. (1996), Smith et al. (1997), Canh et al. (1998), De La Llata et al. (2002), Figueroa et al. (2002) e Gómez et al. (2002a), que observaram piora na taxa de crescimento dos animais, como conseqüência da redução do nível de $\mathrm{PB}$ da ração.

A redução do nível de proteína bruta da ração também não influenciou $(\mathrm{P}>0,10)$ o consumo de ração diário (CRD), como também foi observado por Kerr et al. (1995), Cromwell (1996), Smith et al. (1997), Tuitoek et al. (1997a), Canh et al. (1998), Pieterse et al. (2000) e Figueroa et al. (2002), ao avaliarem o efeito da redução do nível de $\mathrm{PB}$ da ração sobre o desempenho dos animais na fase de terminação.

Entretanto, alguns autores (Miller et al., 1996; De La LLata et al., 2002; Gómez et al., 2002a) verificaram tendência de redução no CRD de animais em terminação mantidos em condições de temperatura ideal, recebendo ração com baixo nível de PB, suplementada com aminoácidos.

A conversão alimentar não foi influenciada $(P>0,10)$ pela redução do nível de proteína bruta das rações com a suplementação de aminoácidos, o que está de acordo com os dados descritos por Miller et al. (1996), Cromwell, (1996), Canh et al. (1998), Pieterse et al. (2000), Figueroa et al. (2002), Gómez et al. (2002a) e Ford (2003), que não notaram influência da utilização da proteína intacta ou de aminoácidos sintéticos sobre a CA de suínos em terminação mantidos em ambiente termoneutro. Entretanto, diferem dos resultados obtidos por Kerr et al. (1995), Tuitoek et al. (1997a), Smith et al. (1997) e De La Llata et al. (2002), em estudos realizados com suínos em terminação mantidos em condições de conforto térmico recebendo rações com baixo nível de PB e suplementadas com aminoácidos.

A inconsistência de resultados de GPD e de CA dos animais alimentados com rações com baixo nível de proteína, suplementadas com aminoácidos pode estar relacionada aos níveis de aminoácidos digestíveis estimados nos ingredientes utilizados no preparo das rações, à relação entre os aminoácidos essenciais e a lisina, entre outros fatores.

Os consumos de lisina (CLD) e de energia digestível (CED) diários não foram influenciados $(\mathrm{P}>0,10)$ pela redução da PB da ração, possivelmente pelo fato de as rações terem sido isolisínicas e isoenergéticas e de o CRD dos animais não ter variado entre os tratamentos, como observado por Smith et al. (1996), que também não registraram variação nos CLD e CED de suínos em terminação alimentados com ração com baixo nível de PB (17,6 a 13,7\%) suplementada com aminoácidos.

Do mesmo modo, Figueroa et al. (2002) não constataram efeito da redução do nível de $\mathrm{PB}$ da ração em 4 unidades percentuais, com suplementação de aminoácidos, sobre o CED de leitoas em terminação mantidas em ambiente termoneutro.

Foi observada diminuição $(\mathrm{P}<0,05)$ gradativa no consumo de nitrogênio (CND) diário, de modo que os animais alimentados com as rações com 13,4 e 12,1\% de PB apresentaram reduções de 31,6 e 35,4\%, respectivamente, em relação àqueles que receberam a ração com $17,3 \%$ de $\mathrm{PB}$, enquanto, 
Tabela 2 - Resultados de desempenho, dos consumos de lisina, nitrogênio (N) e energia digestível (ED) e da eficiência de utilização de nitrogênio para ganho (EUNG), de leitoas em terminação mantidas em ambiente termoneutro

Table 2 - Average performance, intakes of protein, digestible lysine, nitrogen $(N)$ and energy (DE) and $N$ efficiency for gain (NEG) of gilts from 60 to $100 \mathrm{~kg}$ on thermoneutral environment

\begin{tabular}{|c|c|c|c|c|c|c|}
\hline \multirow[t]{2}{*}{$\begin{array}{l}\text { Parâmetro } \\
\text { Parameter }\end{array}$} & \multicolumn{5}{|c|}{$\begin{array}{l}\text { Proteína bruta } \\
\text { Crude protein (\%) }\end{array}$} & \multirow[t]{2}{*}{$\mathrm{CV}(\%)$} \\
\hline & 17,3 & 16,0 & 14,7 & 13,4 & 12,1 & \\
\hline Ganho de peso (g/d) (Weight gain) & $855^{\mathrm{a}}$ & $833^{\mathrm{a}}$ & $873^{\mathrm{a}}$ & $841^{\mathrm{a}}$ & $898^{\mathrm{a}}$ & 10,94 \\
\hline Consumo de ração $(\mathrm{g} / \mathrm{d})$ (Feed intake) & $2375^{\mathrm{a}}$ & $2327^{\mathrm{a}}$ & $2387^{\mathrm{a}}$ & $2332^{\mathrm{a}}$ & $2508^{a}$ & 8,07 \\
\hline Conversão alimentar (g/g) (Feed/gain ratio) & $2,79^{\mathrm{a}}$ & $2,81^{\mathrm{a}}$ & $2,75^{\mathrm{a}}$ & $2,78^{\mathrm{a}}$ & $2,81^{\mathrm{a}}$ & 7,76 \\
\hline Consumo de lisina dig. (Digestible lysine intake) & $18,2^{\mathrm{a}}$ & $17,9^{\mathrm{a}}$ & $18,3^{\mathrm{a}}$ & $17,9^{\mathrm{a}}$ & $19,3^{\mathrm{a}}$ & 8,08 \\
\hline Consumo de $\mathrm{N}(\mathrm{g} / \mathrm{d})^{1}$ (Nitrogen intake) & $65,8^{\mathrm{a}}$ & $59,6^{\mathrm{b}}$ & $56,1^{\mathrm{b}}$ & $50,0^{\mathrm{c}}$ & $48,6^{\mathrm{c}}$ & 7,89 \\
\hline EUNG $(N E G)(\mathrm{gGP} / \mathrm{gN})^{1}$ & $13,0^{\mathrm{c}}$ & $14,0^{\mathrm{c}}$ & $15,5^{b}$ & $16,8^{\mathrm{b}}$ & $18,5^{\mathrm{a}}$ & 7,72 \\
\hline
\end{tabular}

${ }^{1}$ Médias seguidas de mesma letra na linha não diferem $(P<0,05)$, em contrastes múltiplos.

1 Means followed by the same letter in a row do not differ $(P<0.05)$ by multiples contrasts.

$\mathrm{CV}$ - Coeficiente de variação (Coefficient of variation).

nos demais tratamentos, foram obtidos valores intermediários.

De forma inversa, a eficiência de utilização de nitrogênio para ganho (EUNG) apresentou redução gradativa $(\mathrm{P}<0,05)$, observando-se o maior valor nos animais que receberam a ração com 12,1\% de PB, que foi 32,1 e 42,3\%, superior aos valores observados, respectivamente, nos animais que consumiram as rações com 16,0 e 17,3\% de PB.

A variação observada no CND e na EUNG deste trabalho está de acordo com os resultados encontrados por Canh et al. (1998) e Figueroa et al. (2002), que relataram que a redução dos níveis de $\mathrm{PB}$ das rações em quatro unidades percentuais ( 16,5 para $12,5 \%$ ) com a suplementação de aminoácidos reduz o CND. Entretanto, somente Canh et al. (1998) verificaram aumento na retenção de nitrogênio dietético consumido. Confirmando este resultado, Ford (2003) observou redução do nitrogênio excretado nas fezes e na urina de animais alimentados com ração com o mesmo perfil de aminoácidos, porém com o nível de PB reduzido.

Os resultados da avaliação da carcaça, do comprimento de carcaça pelo método brasileiro (CCMB) e pelo método americano (CCMA), da área de olho-de-lombo (AOL), da espessura de toucinho (ETUL), da espessura de toucinho a $6,5 \mathrm{~cm}$ da linha dorso-lombar $\left(\mathrm{ETP}_{2}\right)$ e dos rendimentos de carcaça (RC), de carne magra (RCM), de gordura (RG) e de pernil(RP) das leitoas de $100 \mathrm{~kg}$ mantidas em conforto térmico são apresentados na Tabela 3.

De modo geral, a redução dos níveis de PB não influenciou $(\mathrm{P}>0,10)$ as características de carcaça das fêmeas em fase de terminação. Estes resultados estão de acordo com os descritos por Kerr et al. (1995) para AOL, ETUL e ETP 2 e RCM; Miller et al. (1996) para RC, RCM e RP; Smith et al. (1996) para AOL, RC, ETP 2 e RCM; Tuitoek et al. (1997b) para ETUL, ETP 2 e RCM; Canh et al. (1998) para ETUL e

Tabela 3 - Comprimento de carcaça pelos métodos brasileiro (CCMB) e americano (CCMA), área de olho-de-lombo (AOL), espessura de toucinho (ETUL), espessura de toucinho a $6,5 \mathrm{~cm}$ da linha dorso-lombar $\left(\mathrm{ETP}_{2}\right)$ e rendimentos de carcaça (RC), de carne magra (RCM), de gordura (RG) e de pernil (RP) de leitoas aos $100 \mathrm{~kg}$ mantidas em ambiente termoneutro

Table 3 - $\quad$ Carcass lenght by Brazilian (MBCC) and American (MLC) methods, loin eye area (LEA), backfat thickness (BT), backfat thickness at 6.5 cm from midline $\left(B T P_{2}\right)$, yield s of carcass $(Y C)$, lean $(Y L)$, fat $(Y F)$, and ham $(Y H)$ of gilts from 60 to $100 \mathrm{~kg}$ on thermoneutral environment

\begin{tabular}{|c|c|c|c|c|c|c|}
\hline \multirow{3}{*}{$\begin{array}{l}\text { Parâmetro } \\
\text { Parameter }\end{array}$} & \multirow{2}{*}{\multicolumn{5}{|c|}{$\begin{array}{c}\text { Proteína bruta } \\
\text { Crude protein (\%) }\end{array}$}} & \multirow[t]{3}{*}{$\mathrm{CV}(\%)$} \\
\hline & & & & & & \\
\hline & 17,3 & 16,0 & 14,7 & 13,4 & 12,1 & \\
\hline $\mathrm{CCMB}(M B C C)(\mathrm{cm})$ & $94,1 \mathrm{a}$ & $94,1 \mathrm{a}$ & $95,6 \mathrm{a}$ & $93,3 \mathrm{a}$ & $93,6 \mathrm{a}$ & 3,17 \\
\hline CCMA $(M L C)(\mathrm{cm})$ & $77,5 \mathrm{a}$ & $77,8 \mathrm{a}$ & $78,1 \mathrm{a}$ & $76,3 \mathrm{a}$ & $76,7 \mathrm{a}$ & 3,82 \\
\hline $\mathrm{AOL}(L E A)\left(\mathrm{cm}^{2}\right)$ & $47,9 \mathrm{a}$ & $49,6 a$ & $51,4 \mathrm{a}$ & $48,4 \mathrm{a}$ & $50,4 \mathrm{a}$ & 10,57 \\
\hline $\operatorname{ETUL}(B T)(\mathrm{cm})^{*}$ & $20,8 \mathrm{a}$ & $22,5 \mathrm{a}$ & $20,5 \mathrm{a}$ & $21,8 \mathrm{a}$ & $22,8 \mathrm{a}$ & 14,89 \\
\hline $\mathrm{RC}(C Y)(\%)$ & $83,7 \mathrm{a}$ & $83,0 \mathrm{a}$ & $83,6 a$ & $83,5 \mathrm{a}$ & $84,7 \mathrm{a}$ & 1,51 \\
\hline $\mathrm{RCM}(L Y)(\%)$ & $56,7 \mathrm{a}$ & $57,7 \mathrm{a}$ & $57,3 \mathrm{a}$ & $55,1 \mathrm{a}$ & $57,8 \mathrm{a}$ & 3,67 \\
\hline $\mathrm{RG}_{(F Y)}(\%)$ & $23,7 \mathrm{a}$ & $21,3 \mathrm{a}$ & $22,2 \mathrm{a}$ & $24,4 \mathrm{a}$ & $22,6 a$ & 9,57 \\
\hline $\mathrm{RP}(H Y)(\%)$ & $30,4 \mathrm{a}$ & $30,7 \mathrm{a}$ & $30,6 a$ & $30,2 \mathrm{a}$ & $30,4 a$ & 5,72 \\
\hline
\end{tabular}

* Espessura de toucinho entre a última e a penúltima vértebra lombar (Backfat thickness between last and last but one lumbar vertebra).

CV - Coeficiente de variação (Coefficient of variation). 
Tabela 4 - Pesos absoluto (g) e relativo (\% da carcaça) do fígado, dos rins, do estômago e do intestino de leitoas aos $100 \mathrm{~kg}$ mantidas em ambiente de termoneutro

Table 4 - $\quad$ Absolute $(\mathrm{g})$ and relative (\% of carcass) weights of liver, kidneys, stomach and intestine of gilts of $100 \mathrm{~kg}$ on thermoneutral environment



${ }^{1}$ Médias seguidas de mesma letra na linha não diferem $(P<0,05)$, em contrastes múltiplos.

1 Means followed by same letter in a row do not differ $(P<0.05)$ by multiples contrasts.

CV - Coeficiente de variação (Coefficient of variation).

RCM; Schutte et al. (1999) para ETUL e RCM; e De La Llata et al. (2002) para ETUL, RC e RCM. Esses autores não observaram efeito da substituição de PB intacta por aminoácidos sintéticos em rações para suínos em terminação mantidos em ambiente termoneutro.

Os resultados dos pesos absoluto e relativo dos diferentes órgãos avaliados (fígado, rins, estômago e intestino) são apresentados na Tabela 4.

Os tratamentos utilizados influenciaram $(\mathrm{P}<0,05)$ os pesos absoluto e relativo do fígado ( $26,8 \mathrm{e} 28,1 \%$, respectivamente), que foram superiores no tratamento com $16,0 \%$ de $\mathrm{PB}$, em relação ao nível de $12,1 \%$ de PB.

$\mathrm{O}$ peso do fígado é altamente influenciado pelo nível de PB das rações, uma vez que, quando alto (excesso), aumenta a atividade de enzimas, como a arginase, e os pesos absoluto e relativo (Chen et al., 1998).

Os pesos absoluto e relativo dos demais órgãos (rins, estômago e intestino) não foram influenciados $(\mathrm{P}>0,10)$ pela redução da $\mathrm{PB}$ das rações.

Os resultados estão de acordo com os observados por Gómez et al. (2002b), que relataram que o peso das vísceras está relacionado ao nível de consumo, exceto o peso dos rins e do fígado, que são influenciados pelos níveis de PB.

\section{Conclusões}

A redução do nível de $\mathrm{PB}$ de 17,3 para 12,1\% em rações para leitoas mestiças dos 60 aos $100 \mathrm{~kg}$ mantidas em ambiente termoneutro não influencia negativamente o desempenho e os parâmetros de carcaça, desde que essas rações sejam devidamente suplementadas com os aminoácidos essenciais limitantes.

\section{Literatura Citada}

ASSOCIAÇÃO BRASILEIRA DE CRIADORES DE SUÍNOS - ABCS. Método brasileiro de classificação de carcaça. Estrela: 1973. $17 \mathrm{p}$

BOGGS, D.L.; MERKEL, R.A. Live animal carcass evaluation and selection manual. Toronto: Kendall/Hunt. 199p. 1979.

BUfFINGTON, D.E.; COLAZZO-AROCHO, A.; CANTON, G.H. et al. Black globe-humidity index (BGHI) as comfort equation for dairy cows. Transaction of ASAE, v.24, p.711-714, 1981.

CANH, T.T.; AARNINK, A.J.A.; SCHUTTE, J.B. et al. Dietary protein affects nitrogen excretion and ammonia emission from slurry of growing-finishing pigs. Livestock Production Science, v.56, p.181-191, 1998.

CARSON, M. Amino acid manipulation and phytase utilization impact on nitrogen and phosphorus excretion. Production Information for Missori Pork Producers, p.1-5, 2001.

CHEN, H.Y.; MILLER, P.S.; LEWIS, A.J. The effect of protein intake on growth performance, plasma urea concentration, liver weight, and arginase activity of finishing barrows and gilts. Nebraska Swine Report, p.34-35, 1998.

CROMWELL, G. 1996. Amino acid supplements for pigs. Acesso em: 04/12/2002 Disponível em: http://www.uky.edu/Ag/ AnimalSciences/swine/documents/aminoacidsupplementsfor pigs.pdf.

CROMWELL, G. 2003. Nutrients in swine manure - Potential environmental pollutants. Disponível em: http://www.uky.edu/Ag/AnimalSciences/swine/ documents/nutrientsinswinemanurepotentialpollutants.pdf Acesso em: 01/12/2002.

De La LLATA, M.; DRITZ, S.S.; TOKACH, M.D. et al. Effects of increasing L-lysine $\mathrm{HCl}$ in corn- or sorghum-soybean mealbased diets on growth performance and carcass characteristics of growing-finishing pigs. Journal of Animal Science, v.80, p. $2420-2432,2002$.

FIGUEROA, J.L.; LEWIS, A.J.; MILLER, P.S. et al. Nitrogen metabolism and growth performance of gilts fed standard cornsoybean meal diets or low-crude protein, amino acidsupplemented diets. Journal of Animal Science, v.80, p.29112919, 2002.

FORD, A.L. 2003. Protein vs amino acids ...where less is better? Kempal articles. Disponível em: www.kenpal.on.ca/ ohfaf041.pdf Acesso em: 12/01/2003. 
FÜLLER, M.F. Macronutrient requirements of growing swine. In: SIMPÓSIO INTERNACIONAL SOBRE EXIGÊNCIAS NUTRICIONAIS DE AVES E SUÍNOS, 1., 1996, Viçosa, MG. Anais... Viçosa, MG: Universidade Federal de Viçosa, 1996. p.205-221.

GÓMEZ, R.S.; LEWIS, A.J.; MILLER, P.S. et al. Growth performance, diet apparent digestility, and plasma metabolite concentrations of barrows fed corn-soybean meal diets or lowprotein, amino acid-supplementerented diets at different feeding levels. Journal of Animal Science, v.80, p.644-653, 2002a.

GÓMEZ, R.S.; LEWIS, A.J.; MILLER, P.S. et al. Body composition and tissue accretion rates of barrows fed corn-soybean meal diets or low-protein, amino acid-supplemented diets at different feeding levels. Journal of Animal Science, v.80, p.654-662, 2002b.

JENKINS, J.L. 2000. Dollars and scents: mu swine nutritionist formulates pig diet that reduces odor, maintains performance. Acesso em: 12/01/2003 Dísponivel em: http://www.missouri.edu/ $\sim$ news/releases/octnov00/pigstink.html.

KEER, B.J.; MCKEITH, F.K.; EASTER, R.A. Effect on performance and carcass characteristics of nursery to finisher pigs fed reduced crude protein, amino acid-supplemented diets Journal of Animal Science, v.7, n.3, p.433-440, 1995.

MILLER, P.S.; LEWIS, A.J.; WOLVERTON, C.K. et al. Performance of growing-finishing pigs consuming diets formulated on an ideal protein (first four limiting amino acids) basis. Nebraska Swine Report, p.27-30, 1996.

MURPHY, J. 2002. Strategies to help reduce nutrient excretion in swine manure. Disponível em: http:// www.gov.on.ca/OMAFRA/english/livestock/swine/facts/ info_strategies_reduce_nutrient_excretion.htm. Acesso em: 10/01/2003.

ORLANDO, U.A.D.; OLIVEIRA, R.F.M.; DONZELE, J.L. et al. Níveis de proteína bruta da ração para leitoas dos 30 aos $60 \mathrm{~kg}$ mantidas em ambiente de conforto térmico $\left(21^{\circ} \mathrm{C}\right)$. Revista Brasileira de Zootecnia, v.30, p.1760-1766, 2001.

PIETERSE, E.; SIEBRITS, F.K.; GLOY, E.L. et al. The effect of protein inclusion level in diets formulated to contain an ideal amino acid composition for growing pigs. South African Journal of Animal Science, v.30 (Suppl. 1), p.57-61, 2000.

PUPA, J.M.R.; ORLANDO, U.A.D.; DONZELE, J.L. Requerimentos nutricionais de suínos nas condições brasileiras. In: WORKSHOP LATINO AMERICANO BIOLATINA, NUTRIÇÃO DE AVES E SUÍNOS, 1., 2001, Foz do Iguaçu. Anais... Foz do Iguaçu: 2001. p.143-153.
REESE, D.E.; KOELSCH, R. 2000. Altering swine manure by diet modification. Disponível em: www.ianr.unl.edu/pubs/ swine/g1390.htm. Acesso em: 12/05/2003.

Rhodimet nutrition guide. 2.ed. France: Rhône-Poulenc Animal Nutrition, 1993. 55p.

ROSTAGNO, H.S.; ALBINO, L.F.T.; DONZELE, J.L. et al. Composição de alimentos e exigências nutricionais de aves e suínos: tabelas brasileiras. Viçosa, MG: Universidade Federal de Viçosa, 2000. 141p.

STATISTICAL ANALYSES SYSTEM - SAS. SAS System for Windows, release 8.00 Cary: 1999. 01 CD-ROM.

SHUTTE, J.B. Efeito de um nível de proteína mais baixo sobre o desempenho, qualidade da carcaça $e$ aspectos ambientais e de saúde dos suínos. In: MINI-SIMPÓSIO DE NUTRIÇÃO DE AVES E SUÍNOS, 1999, Viçosa, MG. Resumos... Viçosa, MG: Departamento de Zootecnia, 1999. p.34-60.

SMITH, J.W.; O'QUINN, P.R.; TOKACH, M.D. et al. Effects of low-protein, amino acid fortified diets, formulated on a net energy basis, on th growth performance and carcass characteristics of finishing pigs. Swine Day, p.85-89, 1997.

TAVARES, S.L.S.; DONZELE, J.L.; OLIVEIRA, R.F.M. et al. Influência da temperatura ambiente sobre o desempenho e parâmetros fisiológicos de suínos machos castrados dos 30 aos 60 kg. Revista Brasileira de Zootecnia, v.29, p.199-205, 2000.

TUITOEK, K.; YOUNG, L.G.; de LANGE, C.F.M. et al. The effect of reducing excess dietary amino acids on growing-finishing pig performance: evaluation of the ideal protein concept. Journal of Animal Science, v.75, p.1575-1583, 1997a.

TUITOEK, K.; YOUNG, L.G.; de LANGE, C.F.M. et al. Body composition and protein and fat accretion in various body components in growing gilts feed diets with different protein levels but estimatedto contain similar levels of ideal protein. Journal of Animal Science, v.75, p.1584-1590, 1997b.

van HEUGTEN, E.; van KEMPEN, T. 2000. The science of odor. Swine News, Noth Caroline Cooperative Extension Service, v.24 (9). Acesso em: 12/01/2003. Disponível em: http:// mark.asci.ncsu.edu/Swine_News/2001/sn_v2409.htm. 